Canadian

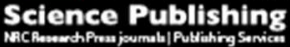

Canadian Journal of Zoology Revue canadienne de zoologie

\title{
Does Prey Density Predict Characteristics of Primiparity in a Solitary and Specialized Predator, the Canada Iynx (Lynx canadensis)?
}

\begin{tabular}{|r|l|}
\hline Journal: & Canadian Journal of Zoology \\
\hline Manuscript ID & cjz-2016-0269.R1 \\
\hline Danuscript Type: & Article \\
\hline Complete List of Authors: & $\begin{array}{l}\text { Reynolds, John; Government of Newfoundland and Labrador, Environment } \\
\text { and Climate Change } \\
\text { Vander Wal, Eric; Memorial University of Newfoundland, Biology } \\
\text { Adams, Barry; Government of Newfoundland and Labrador, Environment } \\
\text { and Climate Change; Government of Newfoundland and Labrador, Service } \\
\text { NL } \\
\text { Curran, Richard; Government of Newfoundland and Labrador, Environment } \\
\text { and Climate Change } \\
\text { Doucet, Christine; Government of Newfoundland and Labrador, } \\
\text { Environment and Climate Change }\end{array}$ \\
\hline \hline Keyword: & $\begin{array}{l}\text { Canada lynx, <i>Lynx canadensis </i>, <i>Lepus americanus </i>, LIFE } \\
\text { HISTORY < Discipline, placental scars, REPRODUCTION < Discipline }\end{array}$ \\
\hline
\end{tabular}


Does Prey Density Predict Characteristics of Primiparity in a Solitary and Specialized Predator, the Canada lynx (Lynx canadensis)?

John J. Reynolds ${ }^{1,6}$, Eric Vander Wal ${ }^{2}$, Barry K. Adams ${ }^{1,4}$, Richard M. Curran ${ }^{1,5}$, and Christine M. Doucet ${ }^{3}$

${ }^{1}$ Wildlife Division, Department of Environment and Climate Change, Government of Newfoundland and Labrador, P.O. Box 8700, 308 Brookfield Road, St. John's, NL, CAN, A1B 4J6. E-mail: John Reynolds (johnreynolds@gov.nl.ca), Barry Adams (barryadams@gov.nl.ca), Richard Curran (rickcurran@gov.nl.ca)

${ }^{2}$ Department of Biology, Memorial University of Newfoundland, 32 Elizabeth Ave., St. John's, NL, CAN, A1B 3X9. E-mail: evanderwal@mun.ca

${ }^{3}$ Wildlife Division, Department of Environment and Climate Change, Government of Newfoundland and Labrador, P.O. Box 2007, 117 Riverside Drive, Corner Brook, NL, CAN, A2H 7S1. E-mail: christinedoucet@gov.nl.ca

${ }^{4}$ Present Address: Service NL, Government of Newfoundland and Labrador, 8 Myer's Avenue, Suite 201, Clarenville, NL A5A 1T5. E-mail: barryadams@gov.nl.ca

${ }^{5}$ Present Address: Box 125, Harbor Main, NL, CAN, A0A 2P0. E-mail:

rickmcurran44@gmail.com

${ }^{6}$ Corresponding author:

Environmental Assessment Division, Department of Municipal Affairs and Environment, Government of Newfoundland and Labrador

P.O. Box 8700

St. John's, NL, CAN, A1B 4J6. 
Tel: (709) 729-0090

Fax: (709) 729-5518

e-mail: johnreynolds@gov.nl.ca 
John J. Reynolds, Eric Vander Wal, Barry K. Adams, Richard M. Curran, and Christine M. Doucet

Does Prey Density Predict Characteristics of Primiparity in a Solitary and Specialized Predator, the Canada Lynx (Lynx canadensis)?

\section{Abstract}

Age at primiparity is a flexible life history trait that purportedly responds to changing population dynamics and variable resource abundance. We examined placental scars in yearling Canada lynx (Lynx canadensis Kerr, 1792) from the island of Newfoundland and used pregnancy rates and litter sizes to indicate primiparity. We modelled these lynx productivity data with snowshoe hare (Lepus americanus Erxleben, 1777) population attributes using seven multiple a priori competing hypotheses. Hare abundance showed peak, decline and increase phases and densities based on capture-mark-recapture estimates ranged from 0.11 to 1.19 hares ha $^{-1}$. Overall yearling pregnancy rate was $23.5 \%$ and the model with hare abundance fitted alone had the most support. However, surprisingly hare abundance explained little (6\%) variation in yearling pregnancy rate. Mean $( \pm \mathrm{SE})$ litter size was $3.51 \pm 0.27$. None of our covariate models provided unequivocal support for predicting yearling litter size. We speculate that individuals may exhibit behavioural plasticity such that they can dampen the impact of primary prey abundance on yearling pregnancy rate by exploiting alternate prey. Furthermore, intraspecific social interactions may provide additional insight into the determinants of pregnancy rate in yearling lynx.

KEY WORDS: Canada lynx, Lynx canadensis, Lepus americanus, life history, placental scars, reproduction 


\section{Introduction}

Life history traits such as age at first reproduction, or primiparity, have implications for demography and population dynamics (Cole 1954; Stearns 1992; Sæther et al. 2013). For many species, mortality rates decrease non-linearly with age; thus early primiparity becomes an advantageous life history tactic for young individuals that are trading-off disproportionately higher probabilities of mortality with the likelihood of failing to reproduce before death (Stearns 2000). Moreover, among competing life history strategies, reproducing early becomes a meaningful tactic to increase one's lifetime reproductive success (Murie and Dobson 1987; Green and Rothstein 1991; Descamps et al. 2006; Martin and Festa-Bianchet 2012) and the reproductive success of one's offspring (Stearns 1992). Primiparity represents a trade-off between somatic growth and reproduction and it is often condition-dependent; where individual condition can be a function of numerous environmental factors. Consequently disentangling the relative importance of factors that influence variation in primiparity will have implications for evaluating trends in population demography and size, particularly in managed populations.

Age of primiparity varies within and among populations (Reiter and Le Boeuf 1991; Sand and Cederlund 1996). Resource availability is a key factor explaining this variation, where high food availability is predicted to lower the age at primiparity (Dobson and Kjelgaard 1985; Dobson and Oli 2001). Within an individual this may operate through higher body mass (Neuhaus et al. 2004; Nilsen et al. 2010) or larger size (Green and Rothstein 1991). A larger size and or mass are important attributes of early reproducers (Sæther and Heim 1993), and may enable young individuals to better accommodate the costs of gestation and lactation (Sæther and Heim 1993; Jorgenson et al. 1993). High resource availability and larger body size may not only 
show immediate benefits to current offspring but can influence an entire cohort and these effects may persist over generations (Lindström 1999).

Resource availability, however, is typically density-dependent and negatively associated with population density (Martin and Festa-Bianchet 2012). Therefore, age at primiparity is predicted to be density-dependent (Gaillard et al. 2000): earlier mean age at primiparity within a population is indicative of smaller populations or populations in a growth phase, where per capita units of available resources are at a surplus (Reiter and Le Boeuf 1991; Dobson and Oli 2001). Therefore, monitoring age at primiparity can provide indirect evidence into resource abundance and population trajectories, particularly in populations where specialist consumers are intimately linked to a few resources.

Few populations are typically as intimately linked as Canada lynx (Lynx canadensis Kerr, 1792) and their resource, the snowshoe hare (Lepus americanus Erxleben, 1777), where hare undergo population peaks and declines in approximately ten year cycles (Elton and Nicholson 1942; Nellis et al. 1972; Brand et al. 1976). Whereas hare dynamics are affected by factors in addition to lynx predation (Stenseth et al. 1997), changes in lynx populations are tied to hare abundance. Following the hare population crash, lynx numbers decline due to the reduction or absence of recruitment (Brand and Keith 1979). Monitoring recruitment indirectly through female reproductive tract analysis (Mowat et al. 1996b; Slough and Mowat 1996) presents an opportunity to better understand factors that affect primiparity in lynx and their potential implications for population dynamics.

We use a long-term data set on lynx productivity and snowshoe hare densities from Newfoundland, Canada. Lynx management is accomplished through trapping season adjustments 
derived from harvest trends; as a result, carcass collections are used for monitoring demography and life history. Here we assess lynx pregnancy rates and litter sizes through placental scar analysis. We couple these reproductive data with systematic capture-mark-recapture estimates of hare abundance to assess the role of prey population attributes and predator allocation in reproduction vs. somatic growth using seven a priori competing hypotheses (Elliott and Brook 2007).

Placental scars from previous reproductive events are generally not retained in lynx (Mowat et al. 1996a), creating uncertainty in confirming primiparity in animals that have experienced multiple breeding seasons. Therefore, we tested our hypotheses using yearling animals only. Specifically, we predict that high prey density will increase yearling pregnancy rate (Brand et al. 1976; Parker et al. 1983; O’Connor 1986) and increase litter size $\left(\mathrm{P}_{1}\right)$. Breitenmoser et al. (1993) predicted that even at the same density, lynx productivity should be higher during a hare increase than during a decline. We expect a positive association between hare population growth trajectory $(\lambda)$ and yearling pregnancy rate and litter size $\left(\mathrm{P}_{2}\right)$. In addition, we test for an interaction between hare density and hare population growth $\left(\mathrm{P}_{3}\right)$. As a larger body size is linked to a lower age at primiparity (Green and Rothstein 1991; Martin and FestaBianchet 2012), we predict yearling productivity to increase with larger body size; as measured using right hind foot length $\left(\mathrm{P}_{4}\right)$. Since food availability may regulate the effect of body size on lynx productivity we tested for such an interaction $\left(\mathrm{P}_{5}\right)$. Environmental conditions experienced during juvenile development can affect the pattern of allocation in future life history traits (Lindström 1999; Beckerman et al. 2002). We predict that lynx cohorts born during higher hare availability should be more likely to reproduce as yearlings and have increased litter sizes $\left(\mathrm{P}_{6}\right)$. Finally, we assess the effects of all covariates using a global model $\left(\mathrm{P}_{7}\right)$. 


\section{Materials and Methods}

\section{Study Area}

This study was conducted on the island of Newfoundland, province of Newfoundland and Labrador, Canada $\left(53^{\circ} 8^{\prime} 7^{\prime \prime} \mathrm{N}, 57^{\circ} 39^{\prime} 37^{\prime \prime} \mathrm{W}\right)$. Newfoundland lies in the boreal ecoregion (Rowe 1972) and consists predominantly of coniferous forest: black spruce (Picea mariana (Mill.) Britton, Sterns \& Poggenb.), balsam fir (Abies balsamea (L.) Mill.) with white spruce (Picea glauca (Moench) Voss) and patchily distributed eastern larch (Larix laricina (Du Roi ) K.Koch). However, mixedwood and deciduous forests occur, consisting of aspen (Populus tremuloides Michx) and white birch (Betula papyrifera Marshall). The island also has extensive areas of peatland, moss, heath-barrens and tundra (Damman 1983).

\section{Hare Density Estimates}

Hare population density in Newfoundland was determined using four spatially distinct trapping grids (Supplementary Fig. S1). Three of the grids were trapped annually from 19992009, while one of the grids was trapped in the same time period except for years 2003 and 2009. Each trapping grid was 500m x 500m and 50 Tomahawk live traps (Model 205, Tomahawk Live Trap Co., Tomahawk, WI) were placed on a 14 x 14 station grid with traps $77 \mathrm{~m}$ apart (Joyce 2001). Each yearly trapping session consisted of opening traps for three nights in midSeptember/early October before the start of the hare hunting season.

For each snowshoe hare trapping session, traps were opened beginning late afternoon (16:30h), baited with alfalfa cubes and fresh apple and checked as early as possible the following morning to minimize the time hares spent in traps. Trapping did not occur if rain or drizzle with low temperatures was forecasted. Hares were not anesthetized but were restrained and handled in 
burlap bags. On initial capture, hares were marked with individually numbered ear tags (Monel No. 3, National Band and Tag Company, Newport, KY) weighed to the nearest $5 \mathrm{~g}$ with a Pesola spring scale, and the right hind foot $(\mathrm{mm})$ was measured. Sex was determined through palpation and visual inspection of the reproductive organs. Hares were then released at the point of capture. Capture and handling protocols were reviewed and approved by the Wildlife Division, Department of Environment and Climate Change, Government of Newfoundland and Labrador to ensure adherence to the guidelines established by the Canadian Council on Animal Care (Canadian Council on Animal Care 2003) as well as those of the American Society of Mammalogists (Sikes et al. 2011). Parks Canada and the Parks and Natural Areas Division, Department of Environment and Climate Change, Government of Newfoundland and Labrador permitted hare trapping within federal and provincial protected areas, respectively.

As sampling was of short duration and hare abundance, not demography, was our primary objective, we used a closed (i.e. no births, deaths, emigration or immigration) population model. Population estimates were generated using the jackknife estimator implemented in program CAPTURE (Otis et al. 1978; White et al. 1982). The jackknife model accounts for heterogeneity in individual capture probability and for snowshoe hare data, displays a minimal and consistent bias over a range of hare abundances (Boulanger and Krebs 1994, 1996). Moreover, for comparing population estimates, it is best to consistently use the same estimator (Boulanger and Krebs 1994). The declining number of recaptures with abundance precluded the use of formal spatially explicit capture-recapture models (Efford et al. 2004) to calculate density. Population density was obtained by dividing the population estimate by the effective area of the grid, 45 ha (Joyce 2001). 
Hare densities from all active grids were averaged for each year across the study area (Supplementary Table S1). Mean hare density from trap grids was modelled as a smoothing function of trapping year with a generalized additive model (GAM) fitted with package mgcv (Wood 2015) in R 3.2.2 (R Development Core Team 2015). GAM estimates were compared to annual hare harvest returns via correlation analysis (Supplementary Fig. S2). All subsequent analyses used GAM-adjusted estimates of mean hare density.

\section{Lynx Life History Data}

Lynx carcasses were collected from licensed trappers on the island of Newfoundland during the 2001-02 through 2009-10 trapping seasons. Trapping seasons generally consisted of a minimum two month open season with the maximum season length of 3.5 months (October 20 to February 1, 2003-04). The lynx trapping season was closed in 2009-2010. However, lynx are captured under a general trapper's licence which includes all furbearing species on the island except beaver. Although not specifically targeted, lynx may still be susceptible to capture. As sample sizes and composition of females was similar to previous years (Supplementary Table $\mathrm{S} 2$ ), data for this closed season was included in the analysis.

As an indicator of body size, we measured right hind foot length (tip of longest distal phalanx to calcaneus) to the nearest $0.5 \mathrm{~cm}$ with a soft tape. To age carcasses, we extracted the lower canines from the mandible. Canines with an apical foramen were considered kittens. All other canines were aged using cementum analysis by Matson's Laboratory, Milltown, MT. Cementum analysis was used to classify animals as yearlings ( 1.5 years) or adults ( $\geq 2$ years).

We stored reproductive tracts frozen in water. We thawed and soaked them in cold water ( $>$ 1hr) to remove blood stains prior to examination following Mowat et al. (1996a). To count 
placental scars, we split uterine horns longitudinally with a hand blade and spread them open on a sheet of acrylic glass. To enhance visibility of scars, the uteri were illuminated from above and below. Scars were identified as bands across each uterine horn, with lighter scarring sometimes extending from these bands. Each scar was classified as 1 of 6 shades (Englund 1970; Lindstrom 1981) with shade 1 scars being diffuse and barely visible and shade 6 scars being dense and dark black. Pregnancy rate was defined as the proportion of females that exhibited one or more scars irrespective of shade. Litter size was determined by counting scars of all shades (Mowat et al. $1996 a)$

\section{Fertility Models}

Generalized linear models were used to examine the importance of prey abundance, prey population growth rate, hind foot length as a measure of body size and cohort effects on pregnancy rate and litter size of potentially primiparous yearling lynx (Table 1). We defined prey abundance as the hare density estimate closest to, but preceding, the lynx breeding season. This was the hare estimate obtained one year before the year of lynx harvest. For example, reproductive tracts analysed from lynx captured in the 2001-02 trapping season show the results of reproduction that occurred in spring 2001. The closest preceding estimate of hare density during this lynx reproductive period is from fall 2000 (see Supplementary Table S1). Hare population growth rate $(\lambda)$ was calculated as the ratio of hare density at year $t+1$ to hare density at year $t$ and indicates population trajectory, i.e., growth or decline. Cohort effects were defined as a two year lag in mean hare density estimates (see Supplementary Table S1). These estimates were closest to the birth-year of yearlings and were assumed to be indicative of the prey abundance conditions encountered during growth and development. Accordingly, hare densities for the 2000-01 and 2010-11 lynx trapping seasons were also required to implement the cohort 
effects and hare population growth rate models, respectively. Prey abundance and cohort effects variables were collinear; therefore, they were not included simultaneously in any models.

As lynx harvest dates ranged from October to January, we considered whether it needed to be controlled for statistically in our models. Capture date was recoded as number of days since beginning of October and we used generalized linear models to examine temporal trends of capture date on morphology (HFL), pregnancy rate and litter size.

All predictor variables were standardized into z-scores before inclusion in models and were implemented using the glm function in R 3.2.2. Pregnancy rate of yearlings was modelled with a binomial error term and logit link function. Litter size models used a Poisson error term with a log link function. Adjusted coefficients of determination (Nagelkerke 1991) were calculated with R package MuMIn (Barton 2014) and Akaike's Information Criterion (AIC) (Burnham and Anderson 2002) was used for model selection.

\section{Results}

\section{Hare Density}

Mean snowshoe hare density exhibited peak and decline phases (Fig. 1a). Hare numbers peaked during the 2001-02 lynx trapping season and then reached a low by 2005-06. Mean density increased through 2008-09 but declined again in 2009-10. Mean (GAM smoothed) densities indicate a peak in 2000-01 and 2001-02 (1.19 hares $\mathrm{ha}^{-1}$ both years) with a low of 0.11 hares $\mathrm{ha}^{-1}$ in 2005-06 resulting in an amplitude of 10.8. Density appeared to peak again in 200809 and then declined but this peak (0.50 hares $\left.\mathrm{ha}^{-1}\right)$ was much lower than in 2000-01/2001-02 Total hare harvest estimates were highly correlated with GAM estimates of hare density $(r=$ 
0.86, Supplementary Fig. S2), indicating that island-wide hare population trends are reflected in the capture-mark-recapture hare density estimates.

\section{Model Results}

There was no detectable effect of harvest date on morphology (coefficient $\pm \mathrm{SE}: \beta=$ $0.0005 \pm 0.0065, P=0.94)$, pregnancy rate $(\beta=-0.003 \pm 0.01, P=0.78)$ or litter size $(\beta=-0.001$ $\pm 0.005, P=0.83)$. Therefore, harvest date was not included in any models.

Overall, $23.5 \%$ of 166 yearlings showed signs of being pregnant. Of the seven candidate models, prey abundance $\left(\mathrm{P}_{1}\right)$ was the most parsimonious $(\triangle \mathrm{AIC}=0.00$, Table 1$)$ and was a statistically significant predictor of yearling pregnancy rate $(\beta=0.50 \pm 0.21, P=0.020$; Fig. 1b). Prey abundance was also significant within the abundance $\times$ growth interaction model $\left(\mathrm{P}_{3}, \beta=\right.$ $0.58 \pm 0.24, P=0.015)$. Hind foot length (HFL) was statistically significant within the morphology only model $\left(\mathrm{P}_{4}, \beta=0.43 \pm 0.20, P=0.030\right)$. No other explanatory variables were significant. Models $\mathrm{P}_{1}$ and $\mathrm{P}_{4}$ had $\Delta \mathrm{AIC}<2$ (Table 1); therefore, these models were equivocal (Burnham and Anderson 2002). Despite the low $\triangle \mathrm{AIC}$, the coefficients of determination (adjusted $R^{2}$ ) indicate that these models each explained less than $6 \%$ of the variation (Table 1 ); appreciating that the Nagelkerke's adjusted $R^{2}$ typically explains less variation than ordinary least squares regression (Smith and McKenna 2013).

Mean $( \pm \mathrm{SE})$ litter size was $3.51 \pm 0.27(n=39)$. Although prey abundance $\left(\mathrm{P}_{1}\right)$, hare population growth $\left(\mathrm{P}_{2}\right)$, morphology $\left(\mathrm{P}_{4}\right)$ and cohort effects $\left(\mathrm{P}_{6}\right)$ had $\Delta \mathrm{AICs}<2$, the null model had the lowest AIC (Table 1). All adjusted $R^{2}$ values of the top models were each $<3 \%$. 


\section{Discussion}

Contrary to Saunders (1961), who suggested that female lynx on the island of Newfoundland do not breed in their first year (i.e., at 22-23 months), we demonstrate that Newfoundland lynx are capable of breeding at 9-10 months. However, we observed that not all yearlings breed (overall pregnancy rate $23.5 \%$ ). Consequently we investigated potential determinants of yearling pregnancy rate in lynx. Of the seven proposed models, we found that hare density was the strongest predictor of yearling pregnancy rate. Despite sufficient sample size to detect that hare abundance had a significant and positive influence on pregnancy rate, the explanatory value of hare density was low $(6 \%)$. We found little support from similar covariates for predicting yearling litter size. Despite common predictions from life-history theory it is apparent that other factors, unexplored here, may be influencing yearling pregnancy rates and litter sizes.

The abundance of alternative prey may better explain yearling primiparity. Despite being a specialist predator, lynx show dietary plasticity during hare declines (O’Donoghue et al. 1998) and in southern regions, where hare densities are generally low, make extensive use of alternate prey (Aubry et al. 2000). Recent evidence indicates that dietary plasticity is especially critical to yearling lynx. When hare populations begin to decline, yearlings increased their use of alternative prey while adults, subadults and dependent juveniles retained a less variable diet (Burstahler et al. 2016). Lynx in Newfoundland also use a variety of prey items: red squirrels (Tamiasciurus hudsonicus Erxelben 1777), meadow voles (Microtus pennsylvanicus Ord, 1815) and various bird species such as ruffed grouse (Bonasa umbellus L., 1766), spruce grouse (Falcipennis canadensis L., 1758), willow ptarmigan (Lagopus lagopus L., 1758) and ducks (Anas spp.) (Saunders 1963; Bridger 2005). Predation on caribou (Rangifer tarandus L., 1758) 
calves has been documented as well (Bergerud 1971). Using isotope analysis, Roth et al. (2007) also suggest that at $66 \%$ snowshoe hare, the Newfoundland lynx diet is less specialized. If Newfoundland lynx are already adapted to acquiring alternative prey, diet breadth expansion by yearlings may not only enhance survival, but permit reproduction as well. In any case, reliance on snowshoe hare typically declines during summer in most lynx populations (Saunders 1963; van Zyll de Jong 1966; Parker et al. 1983; Poole 2003). Therefore, it is conceivable that the abundance of alternate prey, particularly in spring during conception and gestation may be a more direct determinant of yearling pregnancy rates than hare abundance.

Based on our measure of body size, we detected minimal body size effects on pregnancy rate in yearlings. It is suggested that decreased lynx productivity is due to smaller lynx body size resulting from declining hare populations (Brand and Keith 1979; Parker et al. 1983; O’Connor 1986). With little variation explained by our model set we were unable to statistically decompose the pathway from body size to reproduction in yearlings. However, quantitative evidence for body size effects on lynx reproduction is equivocal. Brand and Keith (1979) indicated that visually assessed fat indices, hence body condition, and yearling ovulation rates declined with declining hare abundance, but provided no information on change in body mass. Parker et al. (1983) showed a concomitant decline of yearling pregnancy rates, hare populations and carcass mass, but mass of fat deposits did not differ markedly. In Eurasian lynx (Lynx lynx L., 1758) females, Nilsen et al. (2010) showed that first time ovulators had higher body mass and those with placental scars were lighter. Body mass was also linked to regions with higher prey availability. Conversely, Axnér et al. (2013) found no effect of body mass or body condition on ovulation rate and placental scar counts of early maturing Eurasian lynx. The uncertainty surrounding the role of body size in studies of primiparous individuals may be due to 
imprecision in body size measurements, e.g., hind foot length (Martin et al. 2013). Moreover, in utero estimates of reproduction are retrospective (Axnér et al. 2013) and measurement of mass or condition post mortem may not adequately reflect condition at the onset of reproduction. Wholebody measurements in the field, pre- and post-reproduction, may be more conclusive.

Other authors have indicated that productivity in lynx may depend on factors other than food availability. First, Breitenmoser et al. (1993) suggested with their "core population hypothesis" that when hare density declines, philopatry of offspring increases as yearling females remain on or close to the female parental territory and do not reproduce. Groups of related females have been observed in the field (Mowat and Slough 1998; O’Donoghue et al. 1998). In Newfoundland, congregations of lynx in areas of local hare abundance have been noted (Bergerud 1971); although, age, sex and genetic relationships were unknown. Breitenmoser et al. (1993) and Mowat et al. (2000) suggested that these matrilineal assemblages may be adaptive as it permits the sharing of space and food. Although speculative for lynx, philopatric yearling daughters that inhabit their mother's home range may experience reproductive suppression, which functions to reduce resource competition as in brown bears (Ursus arctos L., 1758) (Støen et al. 2006). Reproductive suppression, although under captive conditions, has been demonstrated to be physiologically possible in Canada lynx (Fanson et al. 2010). Similarly, experiments on lynx farms indicate that yearlings rarely breed even under conditions of high food availability (pers. comm. cited in Breitenmoser et al. (1993)), which suggests a social and or stress constraint. Reproduction may, in part, be socially mediated even if body size or condition permits. Second, when hare populations were at or near a cyclic high and lynx populations were increasing, Quinn and Thompson (1987) reported that 96\% of yearling females showed luteal bodies yet only 33\% showed placental scars. Lynx have traditionally been 
considered induced ovulators and therefore the presence of luteal bodies is an indication of mating. However, lynx can ovulate spontaneously (ovulation without mating) and may even switch between the two strategies: spontaneous ovulation at high lynx density and induced ovulation at low density (Fanson et al. 2010). Therefore, the low proportion of yearlings showing scars indicates that if ovulation is induced, despite high food availability, yearlings may not be physiologically mature enough to maintain pregnancy (Axnér et al. 2013). If ovulation is spontaneous, it may indicate not all yearlings mate. Mowat et al. (1996b) suggested that males may preferentially breed with adults before yearlings. Therefore, yearling pregnancy rates may depend upon the spatial distribution of adults of both sexes. Regardless of ovulation method, male dependent factors such as sperm quality, intensity of male copulations and mating with multiple males also influences female reproductive success in felids (Erofeeva and Naidenko 2012).

None of our models predicted yearling litter size. This is similar to the Eurasian lynx where primiparous litter sizes were independent of body mass and did not vary among years and study sites with different prey availability levels (Nilsen et al. 2010, 2012; Gaillard et al. 2014). Studies on Canada lynx have found little change in litter sizes with changing hare abundance. Parker et al. (1983) did not detect statistically significant differences in yearling scar counts between years as hares declined, nor did Mowat et al. (1996a) during years of hare increase, peak and first year of decline. A longer term study (Slough and Mowat 1996), however, indicated a change in yearling scar counts and hare numbers, but litter sizes did not differ between adults and yearlings similar to Eurasian lynx (Nilsen et al. 2012; Gaillard et al. 2014); demonstrating that yearlings may allocate as much to reproduction as adults. Although the range 
in litter sizes may be greater, Canada lynx may be akin to Eurasian lynx in displaying a common optimal litter size (Gaillard et al. 2014).

Carcass data precludes the assessment of other potential predictors of yearling pregnancy rate. Although we assessed cohort (year) effects, we were unable to test for maternal age (yearlings born to multiparous or primiparous mothers) or maternal mass effects (Jorgenson et al. 1993). Maternal mass in lynx may also be confounded with maternal age as yearlings give birth 2-3 weeks later than adults and their kittens weigh less (Mowat et al. 1996b; Slough and Mowat 1996). Timing of birth may be a factor as in red squirrels where early breeders were born earlier in the season (Descamps et al. 2006). We also could not assess the influence of environmental variables on yearling pregnancy rate. Deviations from average snow depth or ambient temperatures, for example, can affect an individual's energetic balance which may enhance or dampen the effects of absolute food abundance on yearling pregnancy rate (Becker et al. 1998).

This study is one of the first to explicitly and quantitatively investigate determinants of yearling pregnancy rate in Canada lynx. Our results show a statistical relationship between reproduction in yearlings and snowshoe hare density. However, hare density explains remarkably little of the variation in yearling pregnancy rates or litter size. We, therefore, suggest that information on the abundance and use of alternate prey as well as intraspecific social interactions may provide further insight into lynx life history.

\section{Acknowledgements}

This study was facilitated by the Wildlife Division, Dept. of Environment and Climate Change, Government of Newfoundland and Labrador. Mike McGrath provided valuable advice and assistance. Special thanks to Tammy Keats (Joyce) who initiated the snowshoe hare live 
trapping. We are grateful to the many Conservation Officers (Department of Natural Resources, Newfoundland and Labrador) who assisted with carcass collection and hare trapping. We thank Henrik Andrén and anonymous reviewers for helpful comments that improved the manuscript.

\section{References}

Aubry, K.B., Koehler, G.M., and Squires, J.R. 2000. Ecology of Canada lynx in southern boreal forests. In Ecology and conservation of lynx in the United States. Edited by L.F. Ruggiero, K.B. Aubry, S.W. Buskirk, G.M. Koehler, C.J. Krebs, K.S. McKelvey, and J.R. Squires. University Press of Colorado, Boulder. pp. 373-398.

Axnér, E., Payan-Carreira, R., Setterlind, P., Åsbrink, J., and Söderberg, A. 2013. Collection of field reproductive data from carcasses of the female Eurasian lynx (Lynx lynx). Theriogenology, 80(8): 839-849. doi:10.1016/j.theriogenology.2013.06.015.

Barton, K. 2014. MuMIn: Multi-model inference. R package version 1.10.0. Available from http://CRAN.R-project.org/package=MuMIn.

Becker, C.D., Boutin, S., and Larsen, K.W. 1998. Constraints on first reproduction in North American red squirrels. Oikos, 81(1): 81-92. doi:10.2307/3546470.

Beckerman, A., Benton, T.G., Ranta, E., Kaitala, V., and Lundberg, P. 2002. Population dynamic consequences of delayed life-history effects. Trends Ecol. Evol. 17(6): 263-269. doi:10.1016/S0169-5347(02)02469-2.

Bergerud, A.T. 1971. The population dynamics of Newfoundland caribou. Wildl. Monogr. 25: $3-55$.

Boulanger, J., and Krebs, C.J. 1994. Comparison of capture-recapture estimators of snowshoe hare populations. Can. J. Zool. 72(10): 1800-1807. 
Boulanger, J.G., and Krebs, C.J. 1996. Robustness of capture-recapture estimators to sample biases in a cyclic snowshoe hare population. J. Appl. Ecol. 33(3): 530-542.

Brand, C.J., and Keith, L.B. 1979. Lynx demography during a snowshoe hare decline in Alberta. J. Wildl. Manage. 43(4): 827-849.

Brand, C.J., Keith, L.B., and Fischer, C.A. 1976. Lynx responses to changing snowshoe hare densities in central Alberta. J. Wildl. Manage. 40(3): 416-428.

Breitenmoser, U., Slough, B.G., and Breitenmoser-Wursten, C. 1993. Predators of cyclic prey: is the Canada lynx victim or profiteer of the snowshoe hare cycle? Oikos, 66(3): 551-554.

Bridger, K.E. 2005. A comparative study of the dietary habits and helminth fauna of Canada lynx (Lynx canadensis), red fox (Vulpes vulpes) and eastern coyote (Canis latrans) on insular Newfoundland. M.Sc. thesis, Department of Biology, Memorial University of Newfoundland, St. John's, NL.

Burnham, K.P., and Anderson, D.R. 2002. Model selection and multi-model inference: a practical information-theoretic approach. 2nd edition. Springer-Verlag, New York.

Burstahler, C.M., Roth, J.D., Gau, R.J., and Murray, D.L. 2016. Demographic differences in diet breadth of Canada lynx during a fluctuation in prey availability. Ecol. Evol. 6(17): 63666375. doi:10.1002/ece3.2115.

Canadian Council on Animal Care. 2003. Canadian Council on Animal Care guidelines on: the care and use of wildlife. Ottawa, Ontario, Canada. Available from http://www.ccac.ca/Documents/Standards/Guidelines/Wildlife.pdf.

Cole, L.C. 1954. The population consequences of life history phenomena. Q. Rev. Biol. 29(2): $103-137$. 
Damman, A.W.H. 1983. An ecological subdivision of the island of Newfoundland. In Biogeography and ecology of the island of Newfoundland. Edited by G.R. South. Junk Publishers, The Hague, Netherlands. pp. 163-206.

Descamps, S., Boutin, S., Berteaux, D., and Gaillard, J.M. 2006. Best squirrels trade a long life for an early reproduction. Proc. R. Soc. Lond. B Biol. Sci. 273: 2369-2374.

Dobson, F.S., and Kjelgaard, J.D. 1985. The influence of food resources on life history in Columbian ground squirrels. Can. J. Zool. 63(9): 2105-2109. doi:10.1139/z85-309.

Dobson, F.S., and Oli, M.K. 2001. The demographic basis of population regulation in Columbian ground squirrels. Am. Nat. 158(3): 236-247. doi:10.1086/321322.

Efford, M.G., Dawson, D.K., and Robbins, C.S. 2004. DENSITY: software for analysing capture-recapture data from passive detector arrays. Anim. Biodivers. Conserv. 27(1): $217-228$.

Elliott, L.P., and Brook, B.W. 2007. Revisiting Chamberlin: Multiple working hypotheses for the 21st century. BioScience, 57(7): 608-614. doi:10.1641/B570708.

Elton, C., and Nicholson, M. 1942. The ten-year cycle in numbers of the lynx in Canada. J. Anim. Ecol. 11(2): 215-244. doi:10.2307/1358.

Englund, J. 1970. Some aspects of reproduction and mortality rates in Swedish foxes (Vulpes Vulpes), 1961-63 and 1966-69. Viltrevy, 8: 1-82.

Erofeeva, M.N., and Naidenko, S.V. 2012. Spatial organization of felid populations and their reproductive strategies. Biol. Bull. Rev. 2(3): 268-278. doi:10.1134/S2079086412030024.

Fanson, K.V., Wielebnowski, N.C., Shenk, T.M., Vashon, J.H., Squires, J.R., and Lucas, J.R. 2010. Patterns of ovarian and luteal activity in captive and wild Canada lynx (Lynx 
canadensis). Gen. Comp. Endocrinol. 169(3): 217-224.

doi:10.1016/j.ygcen.2010.09.003.

Gaillard, J.-M., Festa-Bianchet, M., Yoccoz, N.G., Loison, A., and Toigo, C. 2000. Temporal variation in fitness components and population dynamics of large herbivores. Annu. Rev. Ecol. Syst. 31: 367-393. doi:10.1146/annurev.ecolsys.31.1.367.

Gaillard, J.-M., Nilsen, E.B., Odden, J., Andrén, H., and Linnell, J.D.C. 2014. One size fits all: Eurasian lynx females share a common optimal litter size. J. Anim. Ecol. 83(1): 107-115. doi:10.1111/1365-2656.12110.

Green, W.C.H., and Rothstein, A. 1991. Trade-offs between growth and reproduction in female bison. Oecologia, 86(4): 521-527.

Jorgenson, J.T., Festa-Bianchet, M., Lucherini, M., and Wishart, W.D. 1993. Effects of body size, population density, and maternal characteristics on age at first reproduction in bighorn ewes. Can. J. Zool. 71(12): 2509-2517. doi:10.1139/z93-344.

Joyce, T.L. 2001. Impact of hunting on snowshoe hare populations in Newfoundland. M.Sc thesis, Department of Zoology, University of British Columbia, Vancouver, BC.

Lindstrom, E. 1981. Reliability of placental scar counts in the red fox (Vulpes vulpes L.) with special reference to fading of the scars. Mammal Rev. 11: 137-149.

Lindström, J. 1999. Early development and fitness in birds and mammals. Trends Ecol. Evol. 14(9): 343-348. doi:10.1016/S0169-5347(99)01639-0.

Martin, J.G.A., and Festa-Bianchet, M. 2012. Determinants and consequences of age of primiparity in bighorn ewes. Oikos, 121(5): 752-760. doi:10.1111/j.16000706.2011.19962.x. 
Martin, J.G.A., Festa-Bianchet, M., Côté, S.D., and Blumstein, D.T. 2013. Detecting betweenindividual differences in hind-foot length in populations of wild mammals. Can. J. Zool. 91(3): 118-123. doi:10.1139/cjz-2012-0210.

Mowat, G., Boutin, S., and Slough, B.G. 1996a. Using placental scar counts to estimate litter size and pregnancy rate in lynx. J. Wildl. Manage. 60(2): 430-440.

Mowat, G., Poole, K.P., and O’Donoghue, M. 2000. Ecology of lynx in northern Canada and Alaska. In Ecology and conservation of lynx in the United States. Edited by L.F. Ruggiero, K.B. Aubry, S.W. Buskirk, G.M. Koehler, C.J. Krebs, K.S. McKelvey, and J.R. Squires. University Press of Colorado, Boulder. pp. 265-306.

Mowat, G., and Slough, B.G. 1998. Some observations on the natural history and behaviour of the Canada Lynx, Lynx canadensis. Can. Field-Nat. 112(1): 32-36.

Mowat, G., Slough, B.G., and Boutin, S. 1996b. Lynx recruitment during a snowshoe hare population peak and decline in southwest Yukon. J. Wildl. Manage. 60(2): 441-452.

Murie, J.O., and Dobson, F.S. 1987. The costs of reproduction in female Columbian ground squirrels. Oecologia, 73(1): 1-6. doi:10.1007/BF00376969.

Nagelkerke, N.J.D. 1991. A note on a general definition of the coefficient of determination. Biometrika, 78(3): 691-692. doi:10.2307/2337038.

Nellis, C.H., Wetmore, S.P., and Keith, L.B. 1972. Lynx-prey interactions in central Alberta. J. Wildl. Manage. 36(2): 320-329.

Neuhaus, P., Broussard, D.R., Murie, J.O., and Dobson, F.S. 2004. Age of primiparity and implications of early reproduction on life history in female Columbian ground squirrels. J. Anim. Ecol. 73(1): 36-43. doi:10.1111/j.1365-2656.2004.00793.x. 
Nilsen, E., Brøseth, H., Odden, J., and Linnell, J. 2010. The cost of maturing early in a solitary carnivore. Oecologia, 164(4): 943-948. doi:10.1007/s00442-010-1713-2.

Nilsen, E., Linnell, J., Odden, J., Samelius, G., and Andrén, H. 2012. Patterns of variation in reproductive parameters in Eurasian lynx (Lynx lynx). Acta Theriol. (Warsz.) 57(3): 217223. doi:10.1007/s13364-011-0066-5.

O’Connor, R.M. 1986. Reproduction and age distribution of female lynx in Alaska, 1961-1971 preliminary results. In Cats of the world: biology conservation and management. Edited by S.D. Millar and D.D. Everett. National Wildlife Federation, Washington, D.C. pp. 311-325.

O’Donoghue, M., Boutin, S., Krebs, C.J., Murray, D.L., and Hofer, E.J. 1998. Behavioural responses of coyotes and lynx to the snowshoe hare cycle. Oikos, 82(1): 169-183.

Otis, D.L., Burnham, K.P., White, G.C., and Anderson, D.R. 1978. Statistical inference from capture data on closed animal populations. Wildl. Monogr. 62: 3-135.

Parker, G.R., Maxwell, J.W., Morton, L.D., and Smith, G.E.J. 1983. The ecology of the lynx (Lynx canadensis) on Cape Breton Island. Can. J. Zool. 61(4): 770-786.

Poole, K.G. 2003. A review of the Canada Lynx, Lynx canadensis, in Canada. Can. Field-Nat. 117(3): 360-376.

Quinn, N.W.S., and Thompson, J.E. 1987. Dynamics of an exploited Canada lynx population in Ontario. J. Wildl. Manage. 51(2): 297-305.

R Development Core Team. 2015. R: A language and environment for statistical computing. R Foundation for Statistical Computing. Vienna. Available from URL http://www.Rproject.org/. 
Reiter, J., and Le Boeuf, B.J. 1991. Life history consequences of variation in age at primiparity in northern elephant seals. Behav. Ecol. Sociobiol. 28(3): 153-160.

Roth, J.D., Marshall, J.D., Murray, D.L., Nickerson, D.M., and Steury, T.D. 2007. Geographical gradients in diet affect population dynamics of Canada lynx. Ecology, 88(11): 27362743. doi:10.1890/07-0147.1.

Rowe, J.S. 1972. Forest regions of Canada. Publication Number 1300. Publishing Division, Information Canada, Ottawa, Ontario, Canada.

Sæther, B.-E., Coulson, T., Grøtan, V., Engen, S., Altwegg, R., Armitage, K.B., Barbraud, C., Becker, P.H., Blumstein, D.T., Dobson, F.S., Festa-Bianchet, M., Gaillard, J.-M., Jenkins, A., Jones, C., Nicoll, M.A.C., Norris, K., Oli, M.K., Ozgul, A., Weimerskirch, H., Berger, A.E.U., and Day, E.T. 2013. How life history influences population dynamics in fluctuating environments. Am. Nat. 182(6): 743-759. doi:10.1086/673497.

Sæther, B.-E., and Heim, M. 1993. Ecological correlates of individual variation in age at maturity in female moose (Alces alces): the effects of environmental variability. J. Anim. Ecol. 62(3): 482-489. doi:10.2307/5197.

Sand, H., and Cederlund, G. 1996. Individual and geographical variation in age at maturity in female moose (Alces alces). Can. J. Zool. 74(5): 954-964. doi:10.1139/z96-108.

Saunders, J.K. 1961. The biology of the Newfoundland lynx (Lynx canadensis subsolanus Bangs). Ph. D. Thesis, Cornell University, Ithaca, New York, USA, Ithaca, New York, USA.

Saunders, J.K. 1963. Food habits of the lynx in Newfoundland. J. Wildl. Manage. 27(3): 384 390. 
Sikes, R.S., Gannon, W.L., and the Animal Care and Use Committee of the American Society of Mammalogists. 2011. Guidelines of the American Society of Mammalogists for the use of wild mammals in research. J. Mammal. 92(1): 235-253. doi:10.1644/10-MAMM-F355.1 .

Slough, B.G., and Mowat, G. 1996. Lynx population dynamics in an untrapped refugium. J. Wildl. Manage. 60(4): 946-961.

Smith, T.J., and McKenna, C.M. 2013. A comparison of logistic regression pseudo $\mathrm{R}^{2}$ indices. Mult. Linear Regres. Viewp. 39(2): 17-26.

Stearns, S.C. 1992. The evolution of life histories. 1st edition. Oxford University Press, Oxford, UK.

Stearns, S.C. 2000. Life history evolution: successes, limitations, and prospects. Naturwissenschaften, 87(11): 476-486. doi:10.1007/s001140050763.

Stenseth, N.C., Falck, W., Bjørnstad, O.N., and Krebs, C.J. 1997. Population regulation in snowshoe hare and Canadian lynx: asymmetric food web configurations between hare and lynx. Proc. Natl. Acad. Sci. U.S.A. 94(10): 5147.

Støen, O.-G., Zedrosser, A., Wegge, P., and Swenson, J.E. 2006. Socially induced delayed primiparity in brown bears Ursus arctos. Behav. Ecol. Sociobiol. 61(1): 1-8. doi:10.1007/s00265-006-0231-z.

White, G.C., Anderson, D.R., Burnham, K.P., and Otis, D.L. 1982. Capture-recapture and removal methods for sampling closed populations. Los Alamos National Laboratory Publication LA-8787-NERP. Los Alamos, New Mexico. 
Wood, S. 2015. mgcv: Mixed GAM Computation Vehicle with GCV/AIC/REML smoothness estimation. Available from http://cran.r-project.org/web/packages/mgcv/index.html [accessed 27 October 2015].

van Zyll de Jong, C.G. 1966. Food habits of the lynx in Alberta and the Mackenzie District, NWT. Can. Field-Nat. 80: 18-23. 
Table 1. Candidate models explaining variation in pregnancy rates and in utero litter sizes in yearling Canada lynx (Lynx canadensis) as a function of snowshoe hare (Lepus americanus) density, hare population dynamics, lynx morphology, cohort effects, and a global model.

\begin{tabular}{|c|c|c|c|c|c|c|c|c|}
\hline \multirow[b]{2}{*}{ Prediction } & & \multirow[b]{2}{*}{ Explanatory variable } & \multicolumn{3}{|c|}{ Pregnancy rate $(n=166)$} & \multicolumn{3}{|c|}{ Litter Size $(n=39)$} \\
\hline & & & $\Delta \mathrm{AIC}$ & $\mathrm{AIC}_{w}$ & $\operatorname{adj} R^{2}$ & $\triangle \mathrm{AIC}$ & $\mathrm{AIC}_{w}$ & $\operatorname{adj} R^{2}$ \\
\hline Intercept & & Null & 4.15 & 0.05 & 0.00 & 0.00 & 0.34 & 0.00 \\
\hline $\begin{array}{c}\text { Prey } \\
\text { abundance }\end{array}$ & $\mathrm{P}_{1}$ & $\begin{array}{c}\text { Mean hare density (MHD) at lynx } \\
\text { trapping season } t\end{array}$ & 0.00 & 0.35 & 0.06 & 1.90 & 0.13 & 0.00 \\
\hline $\begin{array}{l}\text { Prey } \\
\text { population } \\
\text { growth }\end{array}$ & $\mathrm{P}_{2}$ & Hare population growth $\left(\lambda_{\text {hare }}\right)$ & 5.85 & 0.02 & 0.00 & 1.87 & 0.13 & 0.00 \\
\hline $\begin{array}{l}\text { Abundance } x \\
\text { growth }\end{array}$ & $\mathrm{P}_{3}$ & $\mathrm{MHD}+\lambda_{\text {hare }}+\mathrm{MHD} \times \lambda_{\text {hare }}$ & 2.07 & 0.13 & 0.07 & 5.82 & 0.02 & 0.01 \\
\hline $\begin{array}{l}\text { Lynx } \\
\text { morphology }\end{array}$ & $\mathrm{P}_{4}$ & Hind foot length (HFL,cm) & 1.13 & 0.20 & 0.05 & 0.96 & 0.21 & 0.03 \\
\hline $\begin{array}{l}\text { Abundance } \times \\
\text { morphology }\end{array}$ & $\mathrm{P}_{5}$ & $\mathrm{MHD}+\mathrm{HFL}+\mathrm{MHD} \times \mathrm{HFL}$ & 2.11 & 0.12 & 0.07 & 4.81 & 0.03 & 0.03 \\
\hline Cohort effects & $\mathrm{P}_{6}$ & $\begin{array}{c}\text { MHD at } t-1 \text { : prey abundance } \\
\text { level into which yearling was } \\
\text { born }(\mathrm{CE})\end{array}$ & 3.04 & 0.08 & 0.03 & 1.83 & 0.14 & 0.01 \\
\hline Global model & $\mathrm{P}_{7}$ & $\mathrm{MHD} \times \lambda_{\text {hare }}+\mathrm{MHD} \times \mathrm{HFL}$ & 3.80 & 0.05 & 0.09 & 8.79 & 0.00 & 0.03 \\
\hline
\end{tabular}

Note: Values in bold type indicate $\Delta \mathrm{AIC} \leq 2 . \mathrm{AIC}_{w}=\mathrm{AIC}$ weights. Adj $R^{2}=$ Nagelkerke's adjusted $R^{2}$ 
Fig 1. Population trend for snowshoe hare (Lepus americanus) from 2000-01 through 2010-11 and pregnancy rate of yearling lynx (Lynx canadensis) from 2001-02 through 2009-10 on the island of Newfoundland (Canada). (a). Black points are mean hare density estimates which have been smoothed with a generalized additive model (grey lines, solid = mean and dashed $1 \mathrm{SE}$ ). Pregnancy rate (gray bars) follows the pattern of prey abundance. (b). Although there is a significant positive relationship, mean hare density explains little variation in pregnancy rate for yearling lynx. 


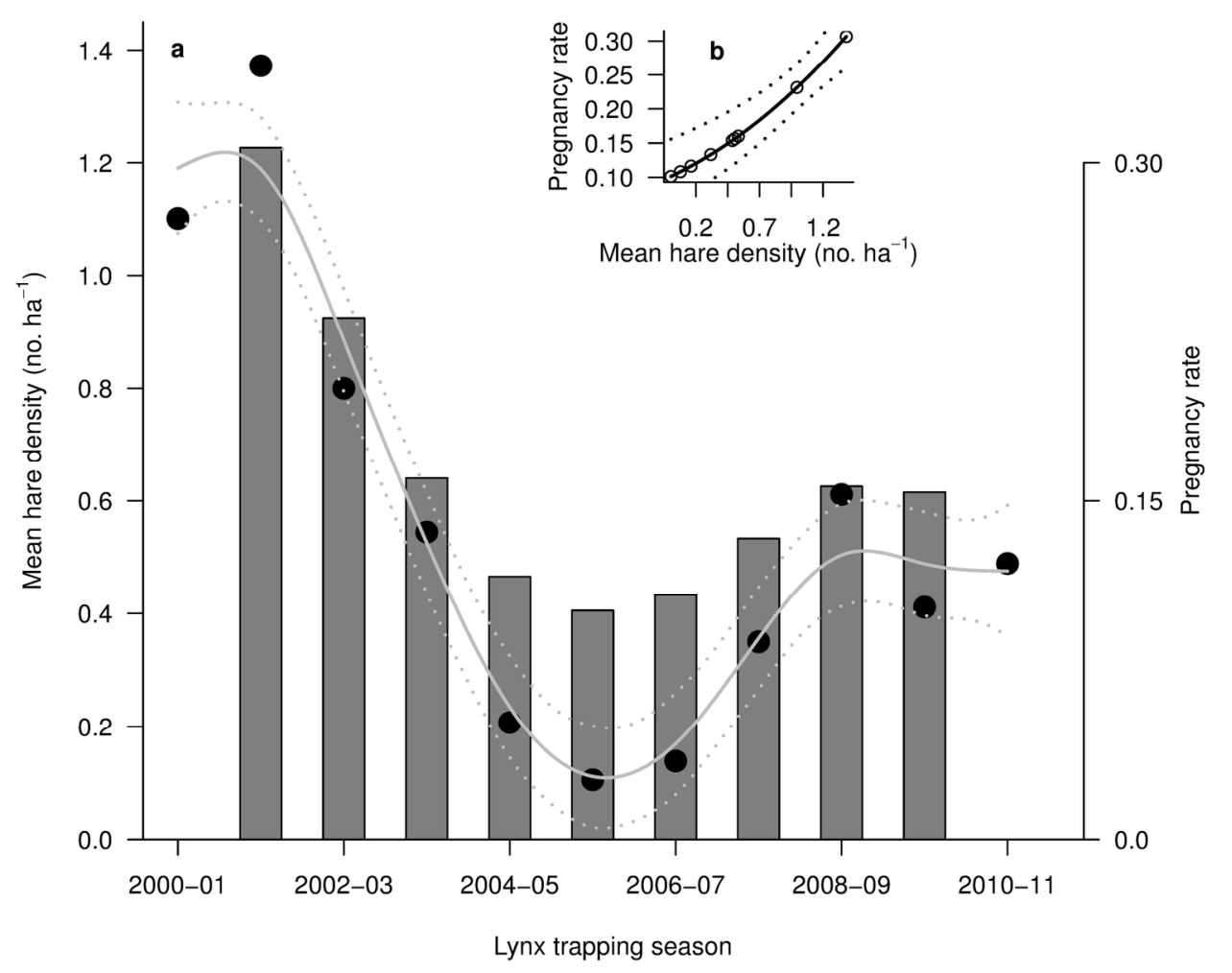

Fig 1. Population trend for snowshoe hare (Lepus americanus) from 2000-01 through 2010-11 and pregnancy rate of yearling lynx (Lynx canadensis) from 2001-02 through 2009-10 on the island of Newfoundland (Canada). (a). Black points are mean hare density estimates which have been smoothed with a generalized additive model (grey lines, solid = mean and dashed 1SE). Pregnancy rate (gray bars) follows the pattern of prey abundance. (b). Although there is a significant positive relationship, mean hare density explains little variation in pregnancy rate for yearling lynx.

$177 \times 150 \mathrm{~mm}(300 \times 300 \mathrm{DPI})$ 